\title{
Navigational Mechanisms of Migrating Monarch Butterflies
}

\author{
Steven M. Reppert, Robert J. Gegear, and Christine Merlin \\ Department of Neurobiology, University of Massachusetts Medical School, Worcester, MA 01605
}

\begin{abstract}
Recent studies of the iconic fall migration of monarch butterflies have illuminated the mechanisms behind the navigation south, using a time-compensated sun compass. Skylight cues, such as the sun itself and polarized light, are processed through both eyes and likely integrated in the brain's central complex, the presumed site of the sun compass. Time compensation is provided by circadian clocks that have a distinctive molecular mechanism and that reside in the antennae. Monarchs may also use a magnetic compass, because they possess two cryptochromes that have the molecular capability for light-dependent magnetoreception. Multiple genomic approaches are being utilized to ultimately identify navigation genes. Monarch butterflies are thus emerging as an excellent model organism to study the molecular and neural basis of long-distance migration.
\end{abstract}

\section{Monarch butterfly migration}

\author{
"Before I sink \\ Into the big sleep \\ I want to hear \\ I want to hear \\ The scream of the butterfly"
}

When The Music's Over - The Doors, 1967

Of course butterflies don't scream (at least at a frequency that humans can hear!). But the biology behind the awe-inspiring fall migration of the eastern North American monarch butterfly (Danaus plexippus) does scream out to be understood. Each fall, like clockwork, millions of monarch butterflies from the eastern United States and southeastern Canada make their remarkable journey to overwinter in roosts in a small area ( $~ 800$ square kilometers) in central Mexico, with some having traveled distances approaching 4000 kilometers [1] (Figure $1 \mathrm{~A}$ and B). The overwintering sites are clustered atop the mountains of Michoacán in central Mexico in a handful of oyamel fir groves.

Due to the long distances traveled and the predictable, repetitive nature of the annual migration cycle, the eastern North American migration is unparalleled among insects [2] and rivals that of birds [3]. The butterfly's relatively simple nervous system, in the face of the same behavioral complexity as manifested by migrating vertebrates, makes monarch migration a revealing case

Correspondence: Steven.Reppert@umassmed.edu.

Disclosure Statement

The authors declare no conflicts of interests.

Publisher's Disclaimer: This is a PDF file of an unedited manuscript that has been accepted for publication. As a service to our customers we are providing this early version of the manuscript. The manuscript will undergo copyediting, typesetting, and review of the resulting proof before it is published in its final citable form. Please note that during the production process errors may be discovered which could affect the content, and all legal disclaimers that apply to the journal pertain. 
study of long-distance navigation among animals [4]. Moreover, the remarkable navigational abilities of monarch butterflies are part of a genetic program that is initiated in migrants - it is not learned, as the butterflies migrating are always on their virgin journey, and those that migrate south are at least two generations removed from the previous generation of migrants [5].

Great strides have been made recently in understanding the navigational aspects of the migration. Most of this work has focused on the mechanisms underlying the butterfly's ability to orient in the southerly direction over the course of the migration, using a time-compensated sun compass. Important discoveries include the nature of the circadian clocks that provide time compensation (their unique molecular mechanism and unusual cellular location), the potential role of a magnetic compass in the migration, and the development of genetic tools that set the monarch apart from other species that undergo long-distance migrations. We highlight these findings, their implications, and the next wave of exciting questions they prompt.

\section{The annual migration cycle}

In the fall, decreasing daylength, cooler temperatures, and aging milkweed (genus Asclepias; the obligate larval food plant) contribute to the environmental events that trigger the migratory generation [6] and the annual migration south begins. However, the precise environmental signals that initiate the migratory state are poorly understood. This area is of critical importance, as understanding the initiating factors would allow for the creation of migrants throughout the year for study of navigation in the laboratory under simulated skylight conditions.

Migrants remain at their overwintering sites in Mexico until the early spring, when the same butterflies reproduce and disperse northward to lay fertilized eggs on newly emerged milkweed plants in the southern United States (Figure 1C). The annual migration cycle is multigenerational, because it takes at least another two generations of spring and summer butterflies that appear to follow the progressive, northward emergence of milkweed to gradually re-populate their home range and thus complete the migration cycle [7]. In the fall, the migration is triggered once again, and the long journey south recommences.

\section{The navigational process}

To navigate across thousands of miles to a precise overwintering location, the butterflies likely need a map and a compass, as used by other long-distance migrants [8]. The aspects of a map sense that are in place in migrants include which direction to fly (southwest) and where to stop (fir groves in central Mexico). However, it is unclear whether migrating monarchs use a "complete" map because of equivocal findings from longitudinal displacement studies $[9,10]$. Moreover, there is no firm evidence that during the migration the butterflies know where they are relative to their destination, at least until they are south of Texas (see below). More is known about the compass sense that migrants use to orient in the southerly direction throughout the day over the course of their migration [11].

It is now commonly thought that the primary compass sense used by migrants is a sun compass [11]. But it is not as simple as just following the sun. As the Earth rotates about its axis, the sun appears to move across the sky from east to west; the sun is thus a moving target, but the butterfly's destination is a fixed point. To compensate for the sun's predictable daily motion, monarchs use a circadian clock, discussed in detail below. Together, the orientation process that uses the sun compass and the circadian clock is more properly known as a timecompensated sun compass - a compass that adjusts itself over the course of the day $[12,13]$.

The use of a time-compensated sun compass by migrating monarchs was first shown by releasing migrants housed under shifted light-dark conditions outdoors (see below) and 
observing their disappearance bearing [14]; a similar approach was used in neotropical migrant butterflies [15]. More recently, precise measurements of flight trajectories from tethered monarch butterflies have been followed during a sustained period of flight outdoors using a flight simulator [16-18] (Figure 2). In contrast to migrants, summer butterflies do not show oriented flight behavior at either the individual or group level $[10,18,19]$.

Could this difference in flight orientation between migratory and summer butterflies be hormonally regulated? One major difference between migrants and summer monarchs is that migrants are juvenile hormone $(\mathrm{JH})$ deficient [20], and it is this deficiency that induces reproductive diapause (quiescence) and increases lifespan - two prerequisites for a longdistance migration. However, JH deficiency is not necessary for persistent time-compensated sun compass orientation in migrants; migrants treated with a JH analog that induces full reproductive function still orient southward over the course of the day $[18,19]$. While it remains possible that $\mathrm{JH}$ deficiency is involved in the induction of directed flight for sun compass orientation, it is clear that persistent JH deficiency is not required for the maintenance of timecompensated sun compass orientation and that sun compass orientation is mediated by a separate mechanism.

The ability of migratory monarchs to successfully navigate requires recalibration of the timecompensated sun compass program by environmental factors [4]. For example, the circadian clock is standardized to local time by dawn and dusk, while the sun compass may be calibrated by geomagnetic forces (see below), and motor output directly influenced by visualizing and thereby avoiding certain landmarks, such as mountains and the ocean.

\section{Illuminating the time-compensated sun compass}

The sun is the most prominent feature of the sky used for sun compass navigation. Scattered sunlight induces the polarization pattern and spectral gradient of skylight, which can also be used as sources of directional information [21,22]. In migratory monarchs, flight simulator experiments have shown that seeing the sun is sufficient for proper flight orientation [17,23]. Less clear is the evidence regarding the relevance of skylight polarization for monarch navigation, as two behavioral studies show its use (M.B. Hyatt, $\mathrm{PhD}$ thesis, University of Pittsburgh, 1993; [23]), while one study failed to do so [24]. Sensing the polarization pattern is not necessary for proper orientation as long as the sun is visible while flying in the simulator [24], consistent with polarized light orientation occurring during cloudy days with some blue sky visible. There is agreement that the detection of polarized light relevant for proper flight orientation is mediated through ultraviolet opsin-expressing photoreceptors in the dorsal rim area of the monarch eye [23,25-27]; the dorsal rim is a small area of the compound eye whose photoreceptors are anatomically specialized for detecting the angle of plane polarized skylight (the electric $[E]$-vector) and which shows high polarization sensitivity.

Evidence is growing about the neuronal processing of skylight cues beyond monarch photoreceptors. In locusts and crickets, neuronal responses to polarized light show the processing of compass information at several brain levels [28,29]. Ultimately, information from both eyes is integrated in the central complex [30], a region also well developed in the monarch brain (S. Heinze and S.M. Reppert, unpublished). Here, an array of neurons possesses $E$-vector tunings that provide a topographical representation of the solar azimuth [28]. It is very likely that this representation is the neuronal correlate of the insect's internal sun compass.

Recordings in locusts have revealed neurons along the polarization input pathway to the central complex that also respond to unpolarized light in a wavelength-dependent manner, making it likely that skylight spectral gradients can generate a robust compass cue for navigation [31, 32]. Similar recordings in the monarch, which are currently underway, show both polarized and unpolarized light responses (S. Heinze and S.M. Reppert, unpublished). 
Because any sun compass used for long-distance flight has to compensate for the daily changes in sun position, the circadian clock is the other essential component of the monarch's navigation system. The importance of the circadian clock in regulating the time-compensated component of flight orientation has been shown in two ways. First, as alluded to above, clock-shift experiments, in which the timing of the daily light-dark cycle is either advanced or delayed, cause predictable alterations in the direction the butterflies fly [14,16,17] (Figure 2). Second, removing the time-compensation clocks (see below) disrupts flight orientation [33].

\section{Focusing on a distinctive circadian clock}

How does the monarch clock work at the molecular level? Like in Drosophila and mammals [34-36], the core mechanism relies on a negative transcriptional feedback loop, which drives self-sustaining rhythms in the mRNA and protein levels of a distinctive set of core clock components (Figure 3A). The monarch clockwork mechanism is unique because it utilizes two distinct CRYPTOCHROME (CRY) proteins; monarchs have both a type 1 Drosophila-like CRY (designated CRY1) that functions as a circadian photoreceptor and a type 2 vertebratelike CRY (designated CRY2) that functions as the major transcriptional repressor of the clockwork feedback loop [37]. The discovery of type 2 vertebrate-like CRYs in insects, which was derived from the initial finding of CRY2 in monarch butterflies [38], has changed our view of how circadian clocks of non-drosophilid insects work and has redefined our understanding of the evolution of animal CRYs [11,39]. Four cells in the dorsolateral region of the central brain (the pars lateralis; PL) house the major circadian clocks in the butterfly brain (Figure 3B); these are the only brain cells in which the transcriptional repressor CRY2 cycles into the nucleus at the appropriate time to regulate the molecular clock feedback loop [37].

The monarch butterfly may also use the CRY proteins as output molecules that define clock circuits in the brain (Figure 3B). Indeed, CRY1-staining fibers extend from the clock cells in the PL to the optic medulla, in which axons of the dorsal rim photoreceptors terminate, suggesting a brain clock modulation of polarized light input [26] (Figure 3B). Other CRY1expressing fibers connect the PL with neurons of the pars intercerebralis (PI), another clock gene/protein-expressing region that may regulate diapause and aging [26]. CRY2-expressing neuronal fibers that may arise from the PI and/or the PL are also found in the central complex, where CRY2 shows circadian oscillations in its expression [37] (Figure 3B).

Based on all the evidence, it was assumed that the circadian clocks necessary for timecompensation of sun compass orientation reside in the PL [11]. However, this was found not to be the case, as discussed in the following section. Thus, much of the brain clock-CRY circuitry is likely involved in aspects of migration (e.g., reproductive diapause and longevity) that are regulated separately from navigation $[18,40]$ and in the circadian regulation of additional activities, including the daily timing of adult eclosion, the sleep-wake cycle and metabolic rhythms. The brain-clock circuit might also be involved in sensing the decreasing day length in the fall, presumably important for triggering the migration south.

\section{Those amazing antennae}

So where do the time compensation clocks reside? Remarkably, they reside in the antennae [33]. Almost 50 years ago, Fred Urquhart, one of the pioneers of research on monarch migration, offered evidence that the antennae might play a role in the flight orientation of migratory monarchs [9]. Now, it is known that the antennae do not just play a role but are required for proper time-compensated sun compass orientation [33] (Figure 4). Monarchs whose antennae have been removed are disoriented, and when the antennae are painted black to block light input, migrants do not orient properly. Clock protein and mRNA levels in the antennae exhibit oscillatory patterns just like those in brain clocks. Even when explanted and examined in vitro, antennal clocks continue to oscillate and can still be entrained by light. This 
finding indicates that they could function independently from the brain as time-compensation components for sun compass orientation. Thus, antennae have circadian clocks that are directly entrained by light, independent from the brain, with molecular clockwork identical to that found in brain clocks, and these clocks actually provide the primary timing component of the sun compass orientation mechanism [33].

These findings open a new line of investigation into clock-compass connections that may extend widely to other insects that use this orientation mechanism (e.g., bees) [41]. They also suggest the existence of a crucial but until now unknown neural circuit between the antennae and the central complex system that is under investigation [33] (Figure 4).

A big question yet to be tackled is how the circadian clock and the sun compass are coupled to ultimately direct the motor system to produce directed flight behavior over the course of the day - the basis behind time-compensated sun compass orientation in any animal. Clearly, refined electrophysiological analysis of the neuronal integration of skylight information in the monarch central complex is needed. Extending these studies to tethered butterflies flying under the outdoor sky is critical.

\section{A magnetic compass?}

Many long-distance migrants (e.g., sea turtles and birds) use the Earth's magnetic field for navigation [42,43]. Specifically, the polarity, intensity, and inclination angle of the Earth's field can provide a reliable source of navigational information. These components can be used to either determine geographic position relative to destination (map sense) or maintain a constant bearing in a particular direction (compass sense) [42,44].

Migratory monarchs can maintain a constant southwesterly direction under dense cloud cover $[45,46]$, an ability consistent with the use of a magnetic compass. However, behavioral support for the use of geomagnetic information by migratory monarchs is weak and contradictory. Indeed, monarchs become disoriented upon exposure to a strong experimentally-generated magnetic field [47], although strong magnetic fields can orient neotropical migratory butterflies [48]. Yet, other studies with monarchs have found that they do not show oriented flight behavior when flown under simulated overcast skies, even in the presence of an externally applied magnetic field [16,24]. However, these experiments were performed either indoors or outdoors using Plexiglas coverings to simulate overcast skies, potentially depriving butterflies of wavelengths of light critical for their magnetic compass to function (see below).

Magnetite, iron oxide particles that could be the substrate for sensing magnetic fields, has been identified in monarchs [49,50]. However, in many cases, animal magnetic detection appears to depend on chemical reactions initiated by specific wavelengths of light $[51,52]$. The most popular chemical reaction model proposes that light-dependent magnetoreception is mediated by radical pair reactions that are generated by CRY [53-55]. Recent genetic and behavioral approaches have shown that light-dependent magnetoreception in Drosophila is in fact mediated by its CRY [56,57]. Furthermore, using a transgenic approach in Drosophila, the functional roles of the two monarch butterfly CRYs in magnetosensitivity have been evaluated [58]. Because monarch butterflies possess both a Drosophila-like CRY and a vertebrate-like CRY, they provide a unique opportunity to directly compare the functional equivalency for magnetosensitivity of each CRY type from the same species in vivo. In fact, each of the two monarch CRYs (CRY1 and CRY2) can rescue magnetosensitivity in CRY-deficient Drosophila and do so in a light-dependent manner, with the critical wavelengths being shorter than $420 \mathrm{~nm}$ [58]. This data indicates that both types of monarch CRY proteins have the molecular capacity to transduce magnetic information. The search is now on for the appropriate light-sensitive behavioral correlate of magnetosensitivity in migrating monarch butterflies. 


\section{Other navigational mechanisms}

The prevailing wind direction (out of the northeast in the fall) and changes in atmospheric pressure also have a marked influence on proper navigation and the progression of the migration $[9,10,59]$. In fact, migrants ride southward on the warm air currents (thermals) that precede the southerly moving cold fronts and the associated drop in barometric pressure [9,10]. By surfing these upward air convections it is felt that migrants can get a free ride and conserve energy $[59,60]$. While riding high, they also appear to correct their orientation to compensate for wind drift [46,59], as has been shown for neotropical and other butterflies [61,62]. Due to riding thermals, much of the actual migration is probably not visible to the naked eye [63]. The use of long-distance monitoring of microchip-implanted free-flying monarchs is a critical next step for accurate assessment of monarch migration flight ways.

Steering southerly is sufficient for the bulk of the migrating monarch's travels. As millions of butterflies begin to approach Texas, they are funneled together by two barriers - the Gulf of Mexico on their left and the Rocky Mountains/Sierra Madre Orientals on their right [10] (Figure 1B). However, once the butterflies continue to approach their destination, how do they find their way to the same grove in Michoacán year after year? We postulate that there is a "destination beacon" that guides the butterflies to this forest. The nature of the destination beacon is not yet known but may involve olfactory cues given off at the overwintering sites by the oyamel trees that reside in the unique pine forest in which the butterflies roost or magnetic cues from field anomalies that occur there [64]. The precise nature of the destination signal is a critical piece of the migration puzzle that needs to be solved.

The antennae may play a major role in many of the aforementioned aspects of the migration. Insect antennae are now known to house multiple sensory modalities; in addition to their well known chemosensory function, they can sense sound, wind and gravity [65-67]. It is thus possible that, in addition to housing time-compensated clocks, monarch antennae sense the changes in barometric pressure and wind direction mentioned above. Their chemosensory function may be equally important for smelling the butterflies' destination as they funnel through Texas.

There is an additional aspect of the monarch migration that has been completely ignored - the influence of social interactions [68]. In contrast to the solitary spring and summer monarchs, fall migrants are gregarious. They form overnight roosts during the journey south and are surrounded by thousands of their mates as they fly from Texas southward [1]. We propose that interactions among the group are essential for a successful migration. For example, there may be pheromonal or acoustic communication among the butterflies. Here, once again, the antennae may loom large in their olfactory and sound sensing capacities.

\section{Somewhere in the genes}

The maiden voyage of migratory monarch butterflies suggests that there is either a genetic basis to the migration or an epigenetic one, because it is possible that all generations of the migratory populations - spring and summer- are capable of being migrants if exposed to the appropriate environmental stimuli. Epigenetic events triggered in migrants leading to the migratory state could involve DNA methylation or histone modification. Genetic or epigenetic mechanisms would both lead to differences in gene expression levels between migratory and summer butterflies.

A monarch brain expressed sequence tag (EST) library has been established and used as a basis for the initial transcriptional profiling comparing migratory and summer butterflies [69]. By treating migrants with a JH analog, it has been possible to isolate genes involved in oriented flight from those involved in other processes that characterize migrants, such as the regulation 
of reproduction and longevity; for example, by comparing gene expression differences between analog-treated migrants (orientation 'on', JH 'on') and untreated summer monarchs (orientation 'off', JH 'on'). Indeed, using this approach, a suite of 40 genes was identified whose differential expression in the brain correlated with oriented flight behavior in individual migrants, independent of JH activity [18]. Further evaluation of these genes will likely provide novel insights into their individual and/or collective importance in migration. In addition, sequencing and annotation of the monarch genome will allow more extensive gene expression profiling.

The monarch genome is, in fact, currently being sequenced and annotated (http://reppertlab.org/tools/monarch-genome/) and once completed this resource will be invaluable for experiments involving resequencing the genomic material from migratory and non-migratory populations $[70,71]$. The idea is that there are genomic differences at the population level that would then help narrow the search for gene expression changes between the summer and migratory states of the migratory populations.

Ultimately, it is essential to be able to alter gene expression in monarchs to evaluate the candidate genes involved in migration. Experiments using RNAi knockdown, by injecting larvae, pupae or adult monarch, have been disappointing (A. Casselman and S.M. Reppert, unpublished). A more viable approach is the application of zinc finger nucleases for targeting specific genes in the monarch genome (for review see [72-74]), as this method does not require embryonic stem cells or cloning techniques. Zinc finger nuclease technology holds great promise for not only knocking genes out but also for knocking reporter tags into specific gene loci in monarchs [75].

\section{Flying high}

In summarizing the progress made in understanding monarch navigation, the monarch butterfly is emerging as a model organism for the study of the molecular and neural basis of long-distance migration. Several tools have already been developed and are being exploited that give the monarch an edge over other long-distance migrants (e.g., migratory birds and sea turtles). These include the availability of the monarch DpN1 cell line [76] that contains a light-driven clock [37], which can be used to assess signaling pathways and novel protein interactions, and to test genomic strategies. Furthermore, an EST library has already been established, the monarch genome will soon be sequenced and annotated, and approaches to manipulate the monarch genome are rapidly moving forward.

Beyond further evaluation of time-compensated sun compass mechanisms, the ways in which the rich array of environmental influences (e.g., wind, atmospheric pressure, and geomagnetic fields) work coordinately with the sun compass are under investigation. It is astounding to think that the monarch brain, no larger than the head of a pin, holds a treasure-trove of navigational mechanisms that keep screaming out to be understood (Box 1).

\section{Box 1}

Outstanding questions in the field of monarch butterfly migration

- What are the environmental cues that trigger migratory behavior?

- Do migrating monarchs have a complete sense of which direction to fly and where to stop along the migration route (ie. a complete "map sense")?

- What is the nature of the neural processing of skylight cues in the brain's central complex, the presumed site of the sun compass? 
- How are the circadian clock and the sun compass coupled to maintain a constant flight direction over the course of the day?

- Do migrating monarch butterflies also use a magnetic compass for orientation?

- How do social interactions influence the migration?

- How does the rich array of environmental cues (e.g., wind, atmospheric pressure, and geomagnetic fields) work coordinately with the sun compass for successful migration?

- Can the use of long-distance monitoring of microchip-implanted free-flying monarchs provide important information about monarch migration flight mechanisms?

- Why do migrants stop at the overwintering grounds in Mexico?

- Are there meaningful changes in gene expression between migrant and summer butterflies that inform the genetic/epigenetic nature of the migration?

- Can multiple methods be developed to alter gene expression in monarchs to provide mechanisms of action of candidate "migration" genes?

\section{Acknowledgments}

We thank Stanley Heinze, Jocelyn Rice, David Weaver, and Monika Bajek for comments. Some of the work discussed was supported by NIH grant R01 GM086794 and NSF grant IOB-0646060.

\section{References}

1. Brower LP. Understanding and misunderstanding the migration of the monarch butterfly (Nymphalidae) in North America: 1857-1995. Journal of the Lepidopterist's Society 1995;49:304385.

2. Holland RA, et al. How and why do insects migrate? Science 2006;313:794-796. [PubMed: 16902129]

3. Thorup K, Holland RA. The bird GPS - long-range navigation in migrants. Journal of Experimental Biology 2009;212:3597-3604. [PubMed: 19880719]

4. Reppert SM. A colorful model of the circadian clock. Cell 2006;124:233-236. [PubMed: 16439193]

5. Brower LP. Monarch butterfly orientation: Missing pieces of a magnificent puzzle. Journal of Experimental Biology 1996;199:93-103. [PubMed: 9317405]

6. Goehring L, Oberhauser KS. Effects of photoperiod, temperature, and host plant age on induction of reproductive diapause and development time in Danaus plexippus. Ecological Entomology 2002;27:674-685.

7. Malcolm, SB., et al. Spring recolonization of eastern North America by the monarch butterfly: successive brood or single sweep migration?. In: Malcolm, SB.; Zalucki, MP., editors. Biology and conservation of the monarch butterfly. Natural History Museum of Los Angeles County; 1993. p. 253-267.

8. Gould JL. Sensory bases of navigation. Curr Biol 1998;8:R731-738. [PubMed: 9778524]

9. Urquhart, FA. The monarch butterfly. University of Toronto Press; 1960.

10. Calvert WH. Monarch butterfly (Danaus plexippus L., Nymphalidae) fall migration: flight behavior and direction in relation to celestial and physiographic cues. Journal of the Lepidopterist's Society 2001;55:162-168.

11. Reppert SM. The ancestral circadian clock of monarch butterflies: role in time-compensated sun compass orientation. Cold Spring Harb Symp Quant Biol 2007;72:113-118. [PubMed: 18419268]

12. von Frisch, K. The dance language and orientation of bees. Belknap Press of Harvard University Press; 1967.

13. Kramer G. Experiments on bird orientation and their interpretation. Ibis 1957;99:196-227. 
14. Perez SM, et al. A sun compass in monarch butterflies. Nature 1997;387:29.

15. Oliveira EG, et al. Do neotropical migrant butterflies navigate using a solar compass? J Exp Biol 1998;201 (Pt 24):3317-3331. [PubMed: 9817829]

16. Mouritsen H, Frost BJ. Virtual migration in tethered flying monarch butterflies reveals their orientation mechanisms. Proc Natl Acad Sci U S A 2002;99:10162-10166. [PubMed: 12107283]

17. Froy $\mathrm{O}$, et al. Illuminating the circadian clock in monarch butterfly migration. Science 2003;300:1303-1305. [PubMed: 12764200]

18. Zhu H, et al. Defining behavioral and molecular differences between summer and migratory monarch butterflies. BMC Biol 2009;7:14. [PubMed: 19335876]

19. Perez, SM.; Taylor, OR. Monarch butterflies' migratory behavior persists despite changes in environmental conditions. In: Oberhauser, KS.; Solensky, MJ., editors. The monarch butterfly: biology and conservation. Cornell University Press; 2004. p. 85-89.

20. Herman WS, Tatar M. Juvenile hormone regulation of longevity in the migratory monarch butterfly. Proc Biol Sci 2001;268:2509-2514. [PubMed: 11749703]

21. Coemans MA, et al. The relation between celestial colour gradients and the position of the sun, with regard to the sun compass. Vision Res 1994;34:1461-1470. [PubMed: 8023458]

22. Wehner R. Polarization vision--a uniform sensory capacity? J Exp Biol 2001;204:2589-2596. [PubMed: 11511675]

23. Reppert SM, et al. Polarized light helps monarch butterflies navigate. Curr Biol 2004;14:155-158. [PubMed: 14738739]

24. Stalleicken J, et al. Do monarch butterflies use polarized skylight for migratory orientation? J Exp Biol 2005;208:2399-2408. [PubMed: 15939779]

25. Labhart T, et al. Specialized ommatidia of the polarization-sensitive dorsal rim area in the eye of monarch butterflies have non-functional reflecting tapeta. Cell Tissue Res 2009;338:391-400. [PubMed: 19876649]

26. Sauman I, et al. Connecting the navigational clock to sun compass input in monarch butterfly brain. Neuron 2005;46:457-467. [PubMed: 15882645]

27. Stalleicken J, et al. Physiological characterization of the compound eye in monarch butterflies with focus on the dorsal rim area. J Comp Physiol A Neuroethol Sens Neural Behav Physiol 2006;192:321331. [PubMed: 16317560]

28. Heinze S, Homberg U. Maplike representation of celestial E-vector orientations in the brain of an insect. Science 2007;315:995-997. [PubMed: 17303756]

29. Sakura M, et al. Polarized skylight navigation in insects: model and electrophysiology of e-vector coding by neurons in the central complex. J Neurophysiol 2008;99:667-682. [PubMed: 18057112]

30. Heinze S, et al. Transformation of polarized light information in the central complex of the locust. J Neurosci 2009;29:11783-11793. [PubMed: 19776265]

31. Pfeiffer K, Homberg U. Coding of azimuthal directions via time-compensated combination of celestial compass cues. Curr Biol 2007;17:960-965. [PubMed: 17524646]

32. Kinoshita M, et al. Spectral properties of identified polarized-light sensitive interneurons in the brain of the desert locust Schistocerca gregaria. J Exp Biol 2007;210:1350-1361. [PubMed: 17401118]

33. Merlin C, et al. Antennal circadian clocks coordinate sun compass orientation in migratory monarch butterflies. Science 2009;325:1700-1704. [PubMed: 19779201]

34. Reppert SM, Weaver DR. Coordination of circadian timing in mammals. Nature 2002;418:935-941. [PubMed: 12198538]

35. Allada R, Chung BY. Circadian organization of behavior and physiology in Drosophila. Annu Rev Physiol 2010;72:605-624. [PubMed: 20148690]

36. Ukai H, Ueda HR. Systems biology of mammalian circadian clocks. Annu Rev Physiol 2010;72:579_ 603. [PubMed: 20148689]

37. Zhu H, et al. Cryptochromes define a novel circadian clock mechanism in monarch butterflies that may underlie sun compass navigation. PLoS Biol 2008;6:e4. [PubMed: 18184036]

38. Zhu H, et al. The two CRYs of the butterfly. Curr Biol 2005;15:R953-954. [PubMed: 16332522]

39. Yuan Q, et al. Insect cryptochromes: gene duplication and loss define diverse ways to construct insect circadian clocks. Mol Biol Evol 2007;24:948-955. [PubMed: 17244599] 
40. Kyriacou CP. Clocks, cryptochromes and Monarch migrations. J Biol 2009;8:55. [PubMed: 19591650]

41. Hammer M, Menzel R. Learning and memory in the honeybee. Journal of Neuroscience 1995;15:1617-1630. [PubMed: 7891123]

42. Lohmann KJ. Sea turtles: navigating with magnetism. Curr Biol 2007;17:R102-104. [PubMed: 17276900]

43. Wiltschko W, Wiltschko R. Magnetic orientation and magnetoreception in birds and other animals. J Comp Physiol A Neuroethol Sens Neural Behav Physiol 2005;191:675-693. [PubMed: 15886990]

44. Lohmann KJ, et al. Magnetic maps in animals: nature's GPS. J Exp Biol 2007;210:3697-3705. [PubMed: 17951410]

45. Schmidt-Koenig K. Directions of migrating monarch butterflies (Danaus Plexippus; Danaidae; Lepidoptera) in some parts of the eastern United States. Behavioural Processes 1979;4:73-78.

46. Schmidt-Koenig, K. Orientation of autumn migration in the monarch butterfly. In: Malcolm, SB.; Zalucki, MP., editors. Biology and conservation of the monarch butterfly. Natural History Museum of Los Angeles County; 1993. p. 275-283.

47. Perez SM, et al. The effect of a strong magnetic field on monarch butterfly (Danaus plexippus) migratory behavior. Naturwissenschaften 1999;86:140-143.

48. Srygley RB, et al. Experimental evidence for a magnetic sense in Neotropical migrating butterflies (Lepidoptera: Pieridae). Animal Behaviour 2006;71:183-191.

49. Jones DS, MacFadden BJ. Induced magnetization in the monarch butterfly, Danaus plexippus (Insecta, Lepidoptera). J Exp Biol 1982;96:1-9.

50. Jungreis SA. Biomagnetism: An orientation mechanism in migrating insects? Florida Entomologist 1987;70:277-283.

51. Phillips JB, Borland SC. Behavioral evidence for use of a light-dependent magnetoreception mechanism by a vertebrate. Nature 1992;359:142-144.

52. Wiltschko R, et al. Two different types of light-dependent responses to magnetic fields in birds. Curr Biol 2005;15:1518-1523. [PubMed: 16111946]

53. Maeda K, et al. Chemical compass model of avian magnetoreception. Nature 2008;453:387-390. [PubMed: 18449197]

54. Ritz T, et al. A model for photoreceptor-based magnetoreception in birds. Biophys J 2000;78:707718. [PubMed: 10653784]

55. Rodgers CT, Hore PJ. Chemical magnetoreception in birds: the radical pair mechanism. Proc Natl Acad Sci U S A 2009;106:353-360. [PubMed: 19129499]

56. Gegear RJ, et al. Cryptochrome mediates light-dependent magnetosensitivity in Drosophila. Nature 2008;454:1014-1018. [PubMed: 18641630]

57. Yoshii T, et al. Cryptochrome mediates light-dependent magnetosensitivity of Drosophila's circadian clock. Plos Biology 2009;7:813-819.

58. Gegear RJ, et al. Animal cryptochromes mediate magnetoreception by an unconventional photochemical mechanism. Nature 2010;463:804-807. [PubMed: 20098414]

59. Gibo, DL. Flight strategies of migrating monarch butterflies (Danaus plexippus L.) in southern Ontario. In: Danthanarayana, W., editor. Insect Flight, Dispersal and Migration. Springer-Verlag; 1986. p. 172-184.

60. Gibo DL, Pallett MJ. Soaring flight of monarch butterflies, Danaus plexippus (Lepidoptera, Danaidae), during the late summer migration in southern Ontario. Canadian Journal of ZoologyRevue Canadienne De Zoologie 1979;57:1393-1401.

61. Chapman JW, et al. Flight orientation behaviors promote optimal migration trajectories in high-flying insects. Science 2010;327:682-685. [PubMed: 20133570]

62. Srygley RB. Compensation for fluctuations in crosswind drift without stationary landmarks in butterflies migrating over seas. Animal Behaviour 2001;61:191-203. [PubMed: 11170709]

63. Gibo DL. Altitudes attained by migrating monarch butterflies, Danaus plexippus (Lepidoptera, Danaidae), as reported by glider pilots. Canadian Journal of Zoology-Revue Canadienne De Zoologie 1981;59:571-572. 
64. Monasterio FO, et al. Magnetism as a complementary factor to explain orientation systems used by monarch butterflies to locate their overwintering areas. Atala 1984;9:14-16.

65. Kamikouchi A, et al. The neural basis of Drosophila gravity-sensing and hearing. Nature 2009;458:165-171. [PubMed: 19279630]

66. Sane SP, et al. Antennal mechanosensors mediate flight control in moths. Science 2007;315:863866. [PubMed: 17290001]

67. Yorozu S, et al. Distinct sensory representations of wind and near-field sound in the Drosophila brain. Nature 2009;458:201-205. [PubMed: 19279637]

68. Kent C, et al. Social context influences chemical communication in D. melanogaster males. Current Biology 2008;18:1384-1389. [PubMed: 18789689]

69. Zhu H, et al. Chasing migration genes: a brain expressed sequence tag resource for summer and migratory monarch butterflies (Danaus plexippus). PLoS One 2008;3:e1345. [PubMed: 18183285]

70. Ackery, PR.; Vane-Wright, RI. Milkweed butterflies, their cladistics and biology: being an account of the natural history of the Danainae, a subfamily of the Lepidoptera, Nymphalidae. British Museum (Natural History); Comstock Pub. Associates; 1984.

71. Smith, DS., et al. The butterflies of the West Indies and south Florida. Oxford University Press; 1994.

72. Beumer KJ, et al. Efficient gene targeting in Drosophila by direct embryo injection with zinc-finger nucleases. Proc Natl Acad Sci U S A 2008;105:19821-19826. [PubMed: 19064913]

73. Meng X, et al. Targeted gene inactivation in zebrafish using engineered zinc-finger nucleases. Nat Biotechnol 2008;26:695-701. [PubMed: 18500337]

74. Remy S, et al. Zinc-finger nucleases: a powerful tool for genetic engineering of animals. Transgenic Res. 2009

75. Moehle EA, et al. Targeted gene addition into a specified location in the human genome using designed zinc finger nucleases. Proc Natl Acad Sci U S A 2007;104:3055-3060. [PubMed: 17360608]

76. Palomares LA, et al. Novel insect cell line capable of complex N-glycosylation and sialylation of recombinant proteins. Biotechnol Prog 2003;19:185-192. [PubMed: 12573024] 
(a)

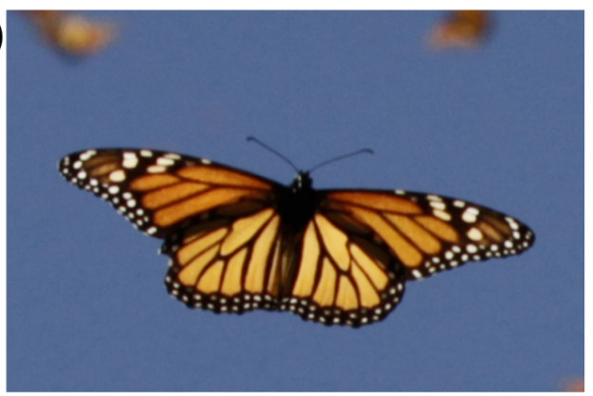

(b)

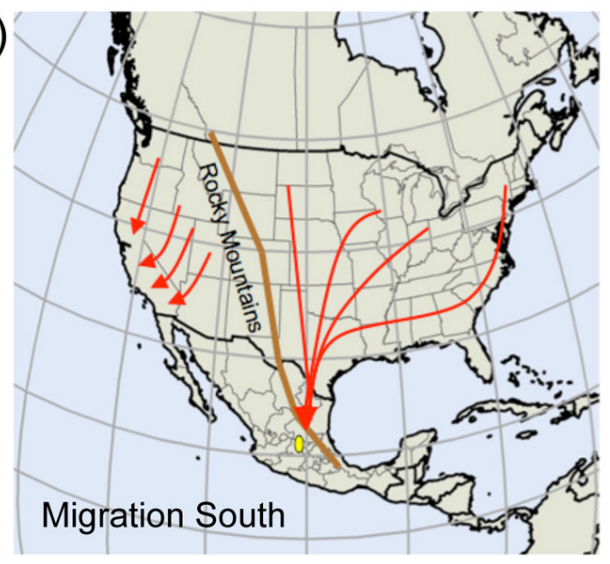

(c)

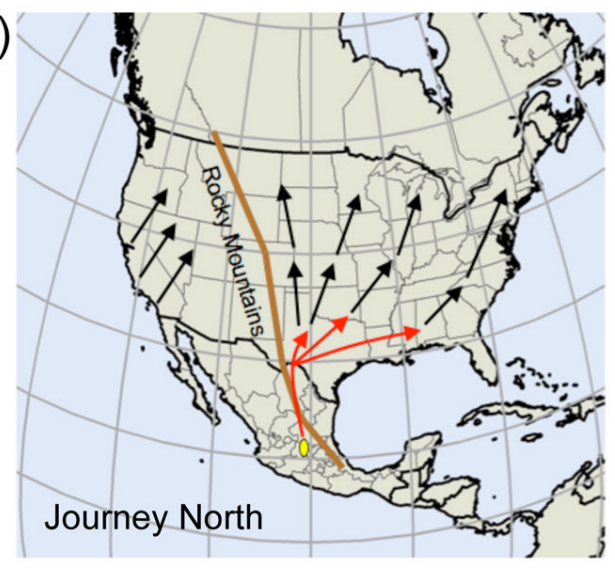

Figure 1. Fall migration of North American monarch butterflies

A. A migrating monarch in flight. Reproduced, with permission, from Monarch Watch (www.monarchwatch.org).

B. Migration south. Eastern North American monarch butterflies undergo a long-distance fall migration (red arrows east of the Rocky Mountains) to a restricted destination in central Mexico (yellow oval). The population of monarch butterflies west of the Rocky Mountains also undergo a fall migration, overwintering in protected roosts along the Pacific Coast (red arrows west of the Rocky Mountains), but the distances traveled are far less than those of the eastern population. In addition, the western range of overwintering areas is not as concentrated as that in the east. Because of the distances traveled and the nature of the focal stopping point, most navigational research has centered on the eastern North American migration.

C. Journey north. The Eastern North American migrants remain at the overwintering areas in Mexico until spring, when the same butterflies reproduce and disperse northward to lay fertilized eggs on newly emerged milkweed in the southern United States (red arrows). 
Successive generations of spring and summer monarchs in the east and the west re-populate the home range (black arrows). 
(a)
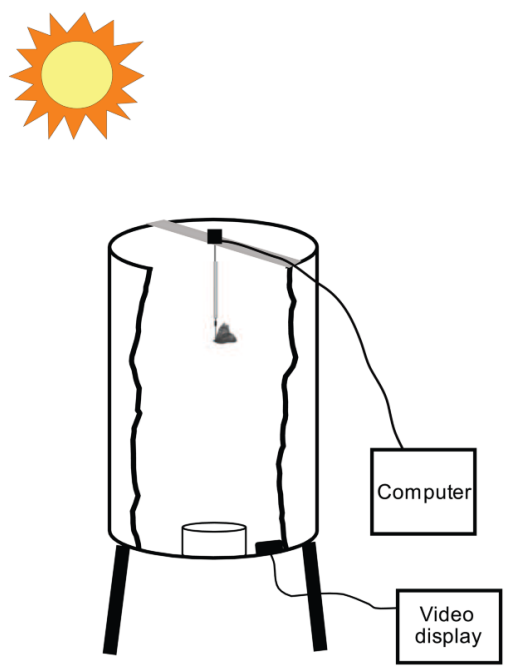

(b)
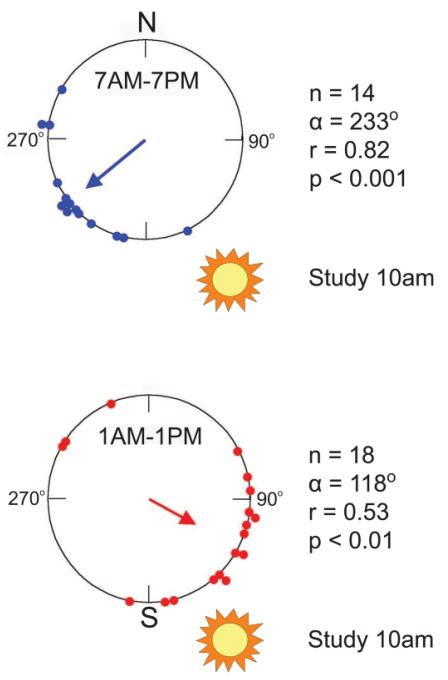

Figure 2. Essential role for a functioning circadian clock in sun compass orientation

A. Flight simulator. An individual monarch butterfly is affixed to a directional recording device using a short length of wire. It may fly and rotate freely, but cannot move vertically or horizontally. The tethered butterfly is suspended in a plastic barrel, excluding buildings and trees from view. During flight, a video recorder monitors the butterfly and the directional recording device sends orientation information to a computer. Adapted, with permission, from Ref. [23].

B. Flight orientation of migrants housed under different lighting conditions. Large circle represents the $360^{\circ}$ of possible direction $\left(0^{\circ}\right.$ is north); small circles represent individual flight orientation of migrants. The arrow indicates mean vector, and the length of the arrow represents strength ( $r$ value). The butterflies in the top graph were housed under normal light/dark conditions in the lab, with simulated sunup at 7 AM and simulated sundown at 7PM. Another group of butterflies (bottom graph) were clock-shifted by 6 hours, with simulated sunup at 1 $\mathrm{AM}$ and simulated sundown at $1 \mathrm{PM}$. So when tested in the flight simulator at $10 \mathrm{AM}$, the normal housed butterflies perceived it to be $10 \mathrm{AM}$ and appropriately oriented to the southwest, with a mean vector $(\alpha)$ of $233^{\circ}$, while the clock-shifted butterflies perceived it to be 4 PM and thereby shifted their oriented counterclockwise by $115^{\circ}$ to the southeast; the sun's azimuth varied from $16^{\circ}$ to $22^{\circ}$ per hour over the course of study, which would result in a 6-hour shift of between $96^{\circ}$ and $132^{\circ}$. This clock-shift experiment shows the importance of the timing of the circadian clock for proper flight orientation. Each butterfly used flew continuously for 10 min. Adapted, with permission, from Ref. [17]. 


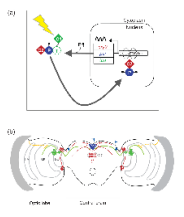

Figure 3. Monarch clockwork model, brain clocks and circuits

A. Molecular clockwork model. The main gear of the clock mechanism is an autoregulatory transcription feedback loop in which CLOCK (CLK) and CYCLE (CYC) heterodimers drive the transcription of the period (per), timeless (tim), and cryptochrome2 (cry2) genes through E box enhancer elements. TIM (T), PER (P), and CRY2 (C2) are translated and form complexes in the cytoplasm; 24 hours later CRY2 is shuttled into the nucleus to inhibit CLK:CYCmediated transcription. PER is progressively phosphorylated and likely helps translocate CRY2 into the nucleus. CRYPTOCHROME1 (CRY1, C1) is a circadian photoreceptor which, upon light exposure (lightning bolt) causes TIM degradation, allowing light to gain access to the central clock mechanism for photic entrainment. The monarch clockwork, which has both Drosophila-like and mammalian-like aspects, was formulated from a combination of in vitro and in vivo approaches, including the use of the monarch DpN1 cell line, which contains a light-driven diurnal clock, and the use of Drosophila transgenesis, to augment the differential clockwork functions of the monarch CRY proteins [37]. Adapted, with permission, from Ref. [37].

B. Schematic representation of brain clocks and circuits in the monarch butterfly brain. Cells expressing TIM, PER, CRY1 or CRY2 are highlighted in blue [26,37]. In these areas the clock proteins partially colocalize. All four clock proteins are co-localized in two of the four cells in the pars lateralis (PL) on each side of the brain; these four cells in total are the bona fide circadian clock cells in brain [26,37]. CRY1-positive cell bodies and projections are represented by green dots and green lines, respectively. Projections from the dorsal rim area photoreceptors are indicated by the dotted orange lines. Neurons and fibers expressing exclusively CRY2 are represented in red and within the central body are shown as red circles and red hatching. PI, pars intercerebralis; PL, pars lateralis; CC, central complex; LA, lamina; ME, medulla; LO, lobula. Adapted, with permission, from Ref. [40]. 


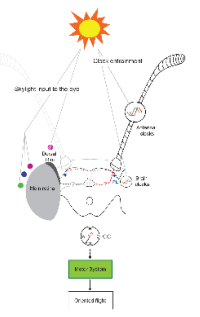

Figure 4. Model of the components and potential circuitry involved in the time-compensated sun compass mechanism

(left) Skylight input to the eye: Skylight cues provide directional information that is sensed by the eye and ultimately integrated into the central complex (CC), the presumed site of the sun compass. The dorsal rim area of the eye senses the angle of plane-polarized, ultraviolet light (small violet circle with crosshatches), while the main retina senses color gradients (small filled violet circle, small blue circle, and small green circle) or senses the sun itself (i.e., does not discriminate between the three colors). Multicircuit pathways, yet to be defined, connect eye-sensed skylight information to the central complex (dashed black and grey lines with question mark).

(right) Clock entrainment: Skylight in the blue range directly entrains (synchronizes) circadian clocks in the antennae and brain to the 24-hour day through direct light action on CRYPTOCHROME1. An as yet unknown neural pathway connects antennal clocks to the central complex (thick dashed red line with question mark); this is a major pathway providing timing information to the central complex. A neural pathway that connects clock cells in the pars lateralis (PL; blue spots) area of the brain to the central complex (thin dashed red line) is likely to exist; this may provide a minor pathway for timing sun compass orientation.

(below) Signal integration: Information from the sun compass and circadian clock is integrated in the central complex itself or in its output pathways. Central complex output pathways communicate with the motor system to ultimately control continuous flight in the southwestly direction. 